\title{
Analysis on the Method and Importance of Practical Teaching in Vocational College
}

\author{
Ruicheng Li \\ Shandong Youth University of Political Science, Jinan 250103, China \\ Tel: 86-531-5899-7405 E-mail: LRC@sdyu.edu.cn
}

Received: May 23, 2011

Accepted: June 17, 2011

doi:10.5539/cis.v4n4p145

\begin{abstract}
Practical teaching is an important part of teaching activities in colleges and universities. Based on the characteristics of vocational colleges, the article expounds the importance of practical teaching in the teaching system of vocational college. Meanwhile it makes an analysis on the current situations and development demand of vocational college, discusses how to make more students make full use of existing practical teaching resources and points out the necessity and urgency to expand the openness of laboratory.
\end{abstract}

Keywords: Practical teaching, Vocational college, Openness of laboratory

\section{Analysis on current situation of vocational college laboratory}

In recent years, part of vocational colleges have one-side attached importance to upgrade from junior college to university, leading to too rapid extensive recruits and insufficient capital in the construction of new university, which directly or indirectly limits the investment in experimental funds. Paying more attention to teaching and less attention to practice is a universal problem(Zhu, Xiangqun, Hu, Chaohui, Liu, Xianghui \& Li, Feng, 2001). In staff allocation and experiment team construction, there are phenomena that some people with low diploma, Logistics miscellaneous persons, relatives and so on are recruited as managers in the laboratory.

Teaching work is divided into theoretical teaching and practical teaching. Because of various reasons, schools often pay more attention to teaching but less attention to practical teaching. Although vocational colleges generally emphasize on quality-oriented education, because of the limitation of various aspects including concept, practical situations and so on, it seems not so optimistic in recent years. There are great differences in the current situations of laboratories and they need to be adjusted and improved urgently(Fang, Zhiming \& Yang, Zhifeng, 2007).

On the one hand, the hardware in laboratories is lag behind, which is shown by that the leaders of colleges didn't attach importance to, the invested fund was little, instrument and equipment is obsolescent and lag behind and the usage efficiency per person is low. Such experimental environment has become the limitation of the target to cultivate applied talents. Only there is a laboratory that has advanced management, persists in the outlook of scientific development and is people-oriented, and further enlarges the openness of laboratory, practical teaching activities are ensured to proceed smoothly and practical teaching quality is improved indeed, and thus the school's teaching quality and level are promoted comprehensively.

Practical teaching is an important part of teaching activities in colleges and universities and is necessary chain of cultivating students' practical ability and innovation ability. Colleges and universities in developed countries pay more attention to cultivating students' thinking independently capacity and innovation awareness in each chain of teaching process, and give students chances to self-express and practice(Zhu, Xiangqun, $\mathrm{Hu}$, Chaohui, Liu, Xianghui \& Li, Feng, 2001). In China, many colleges and universities have gradually established perfect construction and openness mechanism of laboratory after several years' reform and exploration. Qinghua University, Nankai University, Beijing normal university, Beijing Institute of Technology and so on attach great importance to the openness of laboratory and they have been institutionalize basically. That colleges and universities open laboratories is a new way to cultivate creative talents and an important process to carry out experimental teaching reform. Opening laboratory indicts not only the openness of instrument and equipment and the concept of time, but also the openness of experiment curriculum, experiment program and research topic. Therefore, how to make students to make full use of current laboratory resources has become the primary problem to be solved in the management of open laboratory. 
The characteristics of vocational colleges decide that experimental teaching is very important and indispensible chain in total teaching system of vocational colleges. With social development, there are higher requirements for talents in vocational colleges, so talents training target, task and direction in vocational colleges become more definite, specific and socialized. The teaching quality of teaching depends on the professional levels and teaching attitudes of experiment teachers, the appetite of students for knowledge, vocational level of experimenters, the setup of instrument and equipment in laboratory, security measures in laboratory, the management of laboratory and so on. Expanding the openness of laboratory is a feasible and necessary way to solve the practical problem of students in vocational college(Zhang, Xinhua, Liu, Jianxin, 2006).

\section{The development tendency and requirements of practical teaching in China's vocational college}

China is positively exploring and building its own characteristic practical teaching system. Considering that the development of vocational education in China has become international, information-based, diversitized and marketized, the practical teaching of vocational education should also reflects and prompts the tendency. Currently the development tendency of practical teaching in China's vocational college in future are mainly shown as following aspects below(Wei, Zhanzhen, Jiang, Hua, Li, Zhaobin \& Wang, Weizhi, 2007):

\subsection{The proportion of practical teaching in vocational education will still increase}

The increase is not to weaken or strike on theoretical teaching, but to organically integrate part of theoretical knowledge into practical teaching, making theoretical knowledge and skills, and technological application combined closely, even some curriculum or practical modules may merge theoretical knowledge into practical teaching completely and the requisite theory is arranged on the way that supplements what lacks.

\subsection{The operation of practical teaching becomes more socialized}

It is shown specifically: the formulation of practical teaching plan is transformed from "schools first" to "schools, relative enterprises and industries first"; the contents of practical teaching will take professional ability standards formulated by industrial organizations or contents contained by national or international general certificates as basis, in order to realize bilateral direct link. The location of practical teaching will also be conversed from taking Engineering Training Center at school as subjectto taking enterprises as main body; the proportion of part-time teachers from industry and enterprises in full-time teachers is becoming larger gradually, who occupy leading position; besides governmental investment, local enterprises should become main supply channel of capital and equipment in the construction of practical teaching, and they support and participate in the construction of practical teaching infrastructure in the form of donation, rent and cooperation; society and educational administrative department will become the subject of practical teaching evaluation, especially in the aspect of skill training, which should be formulated standards and assessed by enterprises or industry.

\subsection{The operation of practical teaching becomes marketized gradually}

Practical teaching is taken as main teaching activities of cultivating students' vocational ability, whose achievements can be used for commodity exchange; practical teaching equipment, facilities can be used for doing research, developing new products, even directly involving production, and thus produces certain economic benefit; students can adopts suitable method to participate in corporate production.

\subsection{The forms of practical teaching becomes more flexible}

Combined with the implementation of open teaching and development of the credit system(part of credit system), the time span of practical teaching becomes larger, the location is not fixed and the form becomes more flexible.

\section{The implementation of the process of practical teaching}

Practical teaching has its own characteristic, and the objective, task, principle and method of experimental teaching must be clear and definite. The objective of experimental teaching is to make students understand and grasp basic procedure and skills to deal with the problems by way of observation and experiment, and cultivate students' observation ability, thinking ability and practical operational ability throughout the teaching of experiment in the process students obtain or consolidate their knowledge, as well as make students learn the scientific method to know unknown things, including the application of modern technology so as to improve students' comprehensive quality and scientific values.

The main way of practical teaching is experiment. Compared with general classroom instruction, this kind of classroom instruction has such characteristics as practicality and comprehensiveness, so experiment grasp three main teaching links:

1) Preview. Through carefully reading the content of experiment, students understand the objective of the experiment, requirements, principle, procedure, and points for attention. Based on that, the first draft of 
experiment report is finished, whose contents include formula, set-up diagram, circuit diagram, flow chart, data form, coordinate image, and questions related to the experiment.

2) Experiment. After understanding how to use the instrument and its performances, students follow the rule of experimental operation and finish it. Under the premise of understanding experimental principle, both hands and brain are used. Students designed it well, operate it carefully, observe and record primary data timely, accurately, clearly and orderly, pay attention to the changes of the phenomenon at all times, predict experimental results, discover and remove the faults in time, and finally expected conclusion is obtained.

3) Experimental report. Experimental report is the assignment of the class of experiment and the conclusion of the experiment, as well as one of important contents that students strengthen training, so it should be accurate, clear and complete. Completion emphasizes on the inclusion of evaluation and assessment activities, which pays more attention to the grasp situations of scientific method and the participation and development of the subject.

Openness is displayed by students' creativity. Appropriate "knowledge traps" and "knowledge walls" should be set up in experimental teaching in order to show some negative results of experiment and obvious errors far away from expected results so as to motivate students' thought and stimulate their appetite for creativity. The design experiment is also fixed its position as open and explorative experiment, which can push students' creative thinking into the peak, bring the extensive role of experiment into play, associate production with life widely and solve some practical problems.

With the development of modern educational technology, the area of experimental teaching is enlarging continuously. New technologies such as information technology, multi-media technology and network technology provide modernized conditions for experimental teaching. Experiment is the basis of scientific progress and technological development, as well as learning scientific knowledge. In the experiment, modernized technology and method are introduced effectively, which will definitely improve the effect of practical teaching(Lu, Huifen, Pan, Zaiping, Yu, Qiang \& Wen, Yuanxin, 2005).

\section{Case analysis and reference}

The construction and openness of laboratory in Beijing normal university has become institutionalized and their peers may draw lessons from it.

1) Openness. Combined with experimental teaching, Beijing normal university carried out extra-class topic activities and attracted a vast number of students' participation in total university. For example, they hold experimental activities with special topic such as "the match of chemical experimental teaching courseware making" "contest of safety knowledge in laboratory" and so on. The match of "practical cup" food analysis had 33 programs to compete. The number of participants was 101 and there were 76 students to practice in the laboratory involved in 25 programs.

Strengthen system construction in the aspect of school and college and form effective security mechanism and high-efficiency sharing operation mechanism. Integrate experimental teaching resources, prompt sharing and high-efficiency use, unified construct and manage the space of laboratory, form the operation and management mechanism of laboratory between teaching and scientific research. Strength the scientific management of experimental teaching operating process, prompt the construction of experimental teaching team, boost the reform of experimental teaching and enlarge the openness of laboratory.

\section{2) Team construction}

Encourage and strengthen teaching team construction, strength policy guide, combine the introduction and cultivation, improve the quality of experimental teachers. A group of younger doctors and masters worked in experimental teaching. Establish senior experimental technology position, encourage experimental teachers to carry out scientific research and teaching research, set up special funds for teaching research project and carry out experimental teaching reform research. Organize experimental teachers to go out investigating and communicating as well as participating in training. Hold experimental teaching research and training classes and play diffusive role. Strengthen the evaluation of experimental teaching, set up experimental teaching scale, ask students to assess teaching, carry out special inspection of the laboratory construction and organize pro experts and supervisors in experimental teaching to inspect and guide experimental teaching on site.

\section{Conclusion}

There is no doubt about the importance of experimental teaching in the teaching system of vocational colleges. The proportion of practical teaching in vocational education should be strengthened further. To enlarge the 
openness of laboratory and formulate management system with strong operability will improve the effects of practical teaching effectively certainly.

\section{References}

Fang, Zhiming \& Yang, Zhifeng. (2007). Research on open management of laboratory in normal university. SCIENCE \& TECHNOLOGY INFORMATION. No. 14.

Lu, Huifen, Pan, Zaiping, Yu, Qiang \& Wen, Yuanxin. (2005). The Implementation and Application of an Opening Laboratory Information Management System. JOURNAL OF ELECTRICAL \& ELECTRONIC EDUCATION. No. 6.

Wei, Zhanzhen, Jiang, Hua, Li, Zhaobin \& Wang, Weizhi. (2007). On Laboratory's Role in Cultivation of Undergraduate Students. JOURNAL OF BEIJING ELECTRONIC SCIENCE AND TECHNOLOGY INSTITUTE. No. 3 .

Zhang, Xinhua, Liu, Jianxin. (2006). Opening Laboratory for the Training of Qualified Personnel. RESEARCH AND EXPLORATION IN LABORATORY. No. 12.

Zhu, Xiangqun, Hu, Chaohui, Liu, Xianghui \& Li, Feng. (2001). Reform experimental teaching and cultivate students' practical and innovative ability. Experimental Technology and Management. No. 1. 